
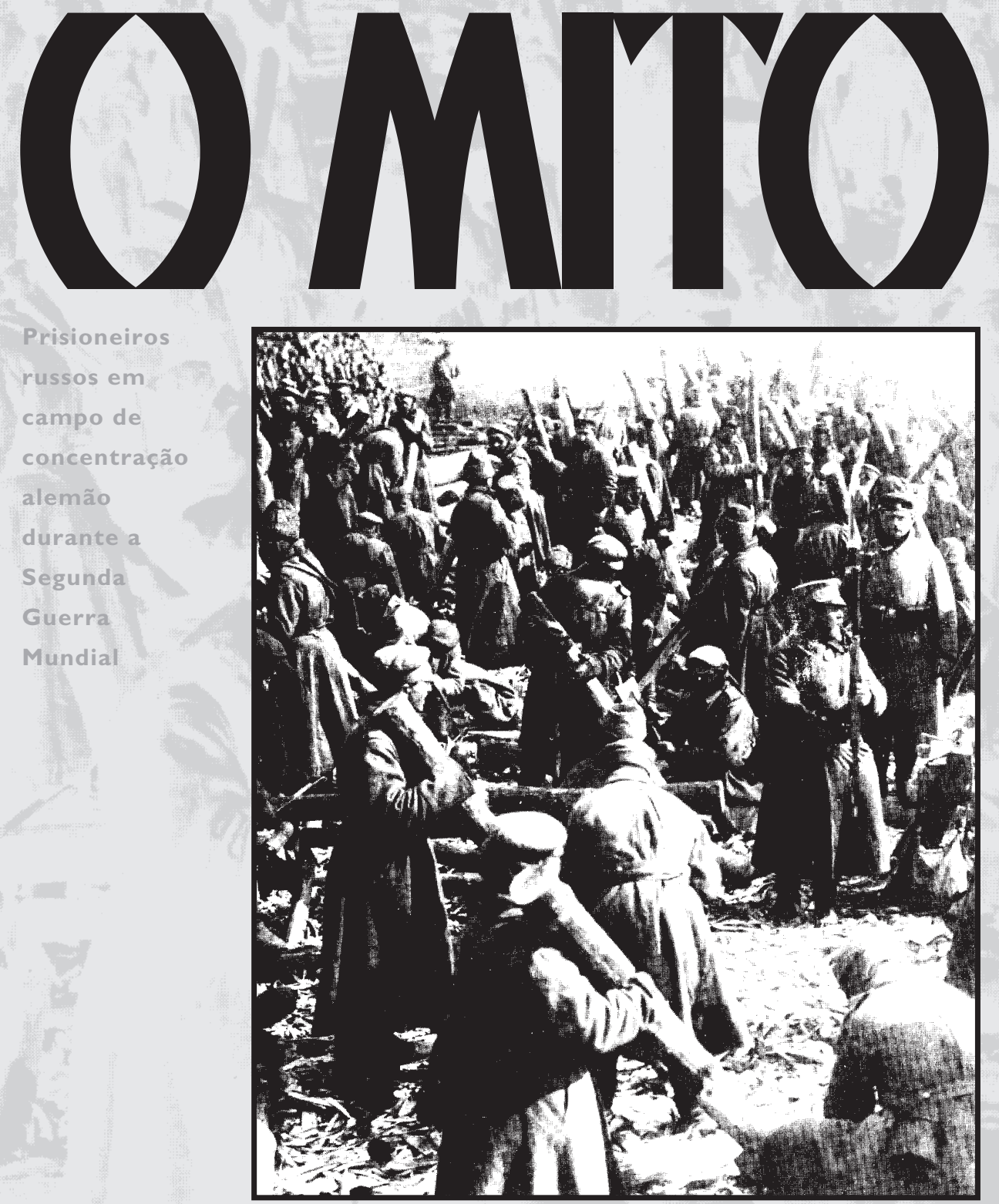

Paulo Bezerra é professor livredocente

de Literatura Russa da USP, tradutor e ensaísta

\title{
Os Escombros
} e o Mito, de Boris Schnaiderman, São Paulo,Companhia das Letras, 1997.
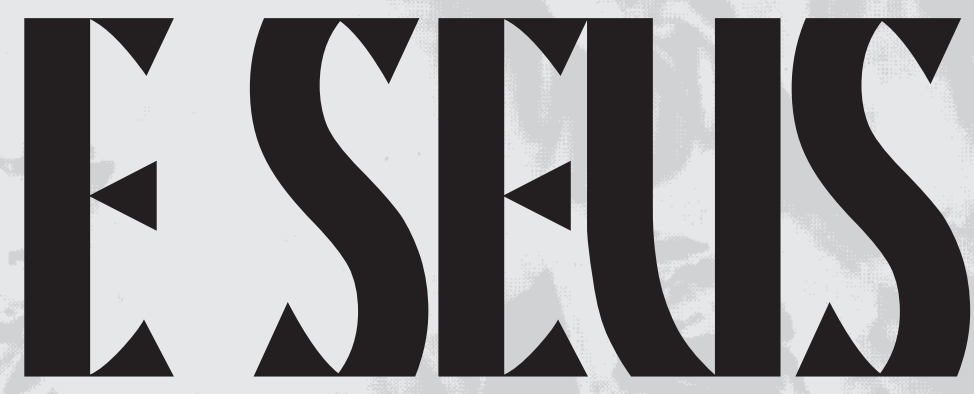

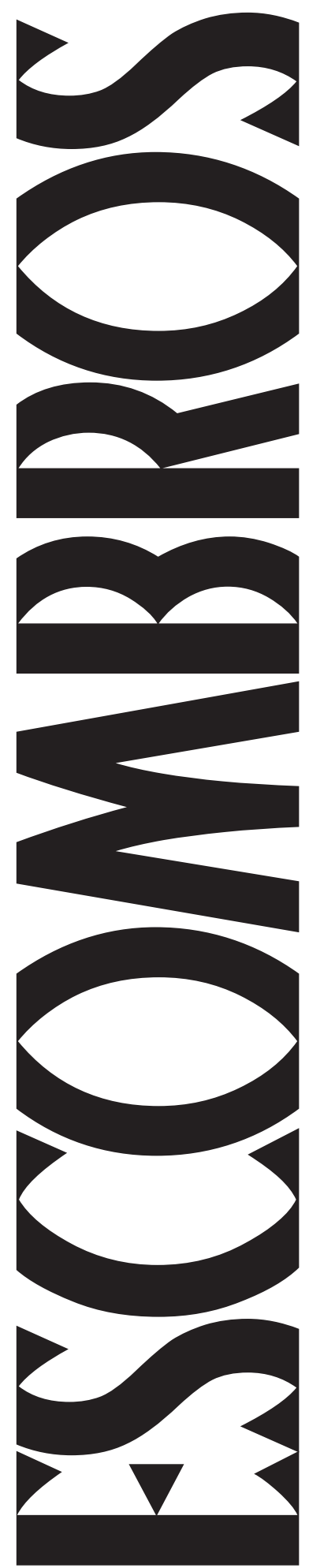

Três trabalhadores soviéticos estão conversando em um campo de trabalhos forçados, e surge entre eles a curiosidade de saber as razões que os levaram àquele local. Trava-se entre eles o seguinte diálogo.

Primeiro trabalhador.

- Eu era um trabalhador exemplar, sempre chegava ao meu emprego meia hora antes do início, acabei sendo acusado de espião da produção socialista e condenado a alguns anos de prisão.

Segundo trabalhador.

- Eu era de uma pontualidade exemplar, chegava sempre na hora exata de começar a trabalhar, fui acusado de comodismo pequeno burguês e condenado a alguns anos de prisão em regime de trabalho forçado.

Terceiro trabalhador.

- Eu sempre chegava atrasado, fui acusado de sabotador da produção socialista e condenado a alguns anos de prisão.

Essa piada mostra a profunda instabilidade da condição do ser humano em um regime totalitário, a imensa dificuldade de pôr o seu relógio histórico em sincronia com o relógio do sistema. O humor negro que ela encerra traduz o espírito sinistro que esteve por trás de toda a vida soviética 
desde o momento em que Stálin começou a escalada devastadora em direção ao poder absoluto e à montagem do sistema nefasto que ficaria conhecido como stalinismo. Apesar do pessimismo que encerra, esse humor traduz, igualmente, a capacidade de resistência da cultura ao escamoteamento da verdade histórica em um país que sempre procurou vender a imagem de paraíso do trabalho, da liberdade e da cultura. As diversas formas de resistência da cultura ao escamoteamento daquela verdade e a relação difícil e muitas vezes trágica da intelectualidade com o poder soviético desde os seus primeiros dias e depois com o sistema stalinista são tema central de Os Escombros e o Mito, livro

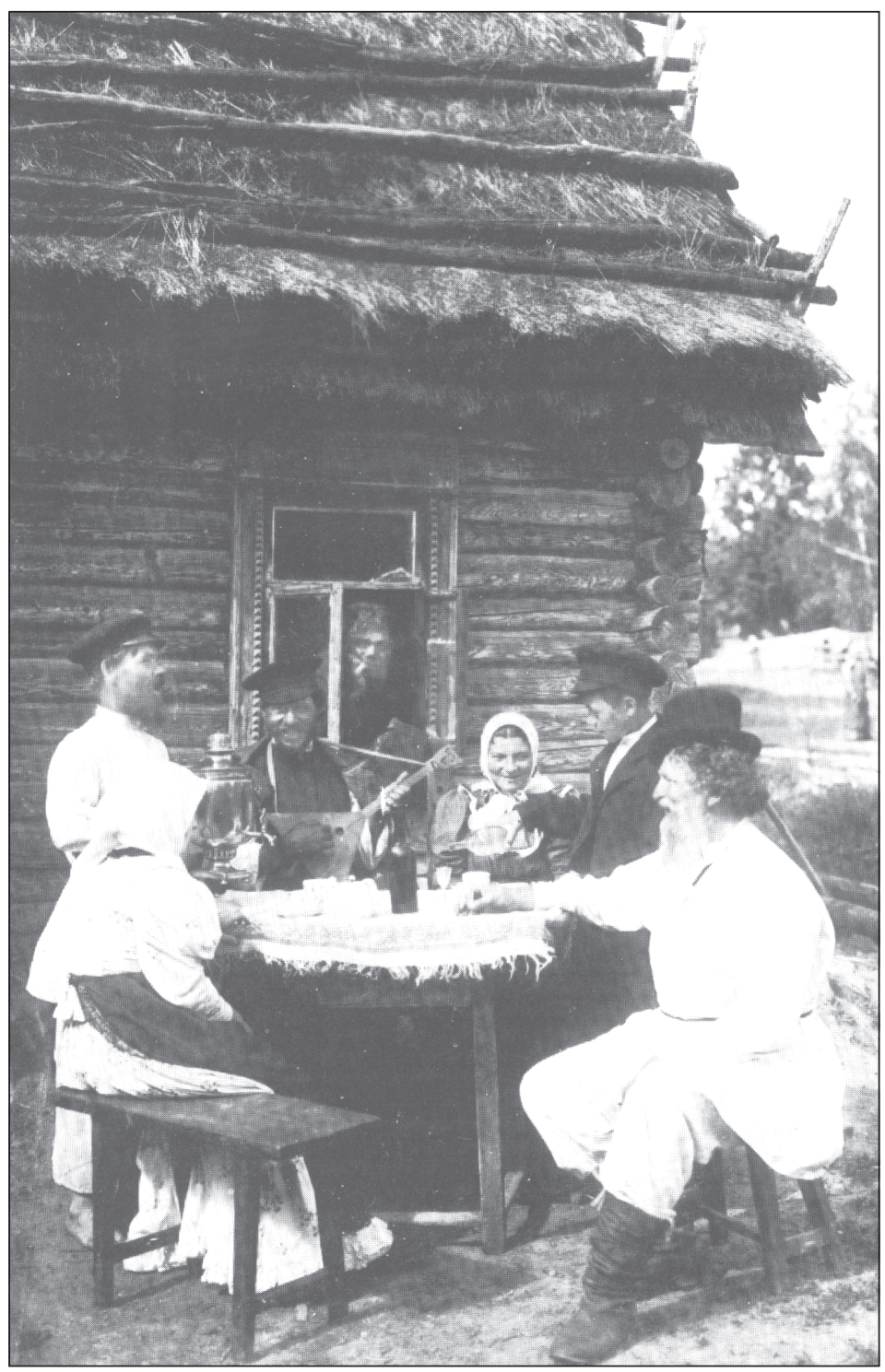

através do qual Boris Schnaiderman mergulha ampla e profundamente na história dessa relação, e procura respostas para questões que até hoje nos perturbam a mente.

Mestre Boris concatena fatos e idéias com uma habilidade que revela um pensamento dotado de uma impressionante pujança juvenil, arrola mais de seiscentos autores e personalidades diversas e visita número aproximado de fontes, entre livros, jornais, revistas, diários, biografias, cartas, poemas, peças musicais, além de fotografias, quadros e filmes, entrevistas e depoimentos pessoais, recriando um quadro histórico e cultural de vastidão e densidade que ultrapassam os limites do objeto que se propõe analisar. Assim, ele nos coloca em um redemoinho de fragmentos históricos, fazendo-nos deparar ora com momentos que antecedem a Revolução de Outubro, ora com os seus primeiros dias de vida e seu desdobramento nas sete décadas que sucederam 1917. Coerente com a proposta contida no subtítulo do livro, concentra sua atenção no período propriamente soviético e nos dá uma visão diacrônica do todo, permitindo-nos acompanhar o movimento pendular em que irá estribar-se a relação da arte, da ciência e de outras formas de pensamento com o poder soviético, mostrando a profunda complexidade dessa relação desde os primeiros momentos da Revolução até o desmoronamento final da União Soviética.

Em A Era das Revoluções, no capítulo especialmente dedicado às artes, Eric Hobsbawn mostra que toda revolução coloca suas necessidades e exigências específicas diante das artes e estas sempre gravitam em torno de idéias que, em diferentes formas e proporções, estão vinculadas a ideais revolucionários. Com a Revolução de Outubro não poderia ser diferente, ainda mais considerando que as artes russas, especialmente a literatura, estiveram constantemente ligadas às idéias avançadas de sua época. A relação entre literatura e ideais revolucionários na Rússia remonta ao romantismo, mas foi com a Revolução que o problema se radicalizou, pois ela colocou na ordem do dia o tema "arte e 
revolução", que se desdobrou posteriormente em "arte e luta de classes", "arte e povo", "arte e ideologia". Como a ideologia assumia um sentido estritamente pragmático e era ela que sedimentava a arte, esta ganhava importância não tanto pela verdade que podia ensejar quanto pelo fato de servir como instrumento à "classe" que estava no poder. Aí residem as fontes dos problemas que acabaram redundando em tragédia da melhor parcela da intelectualidade soviética, tema marcante no livro de mestre Boris.

O livro começa discutindo o período da glasnost, enfatizando a vez do jornalismo, que, depois de desempenhar durante décadas meras funções de boletins oficiais de estilo triunfalista, passa a expor as mazelas da sociedade, mostrando um mundinho bastante torpe, uma sociedade que, em muitos aspectos, quase nada difere das sociedades mais atrasadas e desumanas do chamado Terceiro Mundo. É o caso de uma reportagem sobre a exploração e o mau trato dispensado a crianças, que um repórter publica com tintura de esquerda em um periódico de direita. E Boris observa que a penetração do capitalismo mais selvagem e predatório acaba favorecendo a "estranha aliança entre os comunistas e os direitistas mais extremados". Será que essa aliança é mesmo estranha?

Em livro publicado em 1994 (que me chegou às mãos recentemente) e que leva o título sintomático de Navajdiénie (Alucinação), Aliesksandr Yákovliev, ex-assessor de Gorbatchov, considera o bolchevismo a variante russa do fascismo. Sem entrar no mérito dessa tese, em si mesma muitíssimo discutível, a análise desenvolvida por esse cientista político, respaldada em dados reais, demonstra, de forma inequívoca, que o stalinismo foi um sistema descaradamente direitista, e dirigentes soviéticos até do período do degelo, como Mikoyan e Khruschov, sancionaram pessoalmente as repressões e o extermínio de milhares de pessoas. Dessa perspectiva, a aliança entre comunistas e direitistas extremados na Rússia deixa de ser “estranha”, uma vez que os comunistas russos (há exceções, evidentemente!) são produto desse sistema descaradamente direitista e totalitário que foi o stalinismo, que Khruschov tentou suavizar mas que devorou o próprio Khruschov e conseguiu reimplantar-se com Briejniev sob a forma hoje conhecida de neo-stalinismo. Aliás, só depois das publicações da glasnost ficou-se sabendo da simpatia de Stálin por Hitler, a quem o ditador soviético chamou certa vez de "gênio", que em pouco tempo transformara em potência mundial um país arruinado e subordinara o seu povo à sua vontade. Em fins de junho de 1940 Churchill enviou uma carta a Stálin, prevenindo-o contra a expansão alemã. Além de não responder à carta de Churchill, Stálin ainda transmitiu seu conteúdo a Hitler através de Molotov. Hitler ficou comovido com a lealdade de Stálin. A essa altura já estava assinado o tristemente famoso pacto Molotov-Ribbentrop, mas antes Stálin removera um sério obstáculo chamado Litvínov, medida aplaudida pelo chefe da diplomacia hitlerista, segundo quem Stálin agiu com muita sabedoria, substituindo o judeu Litvínov pelo ariano Molotov (1). O pacto militar foi seguido de um Tratado de Amizade entre a URSS e a Alemanha fascista, celebrado no Krêmlin com discursos amistosos de Stálin, Molotov e Ribbentrop, coisa de deixar estupefato qualquer democrata moderado. Mas Stálin lançou a célebre frase "apenas troquei o fuzil de ombro!", que seus devotos seguidores interpretaram como medida para ganhar tempo.

Os pontos em comum entre os dois tiranos estendem-se também ao campo das artes. A arte de vanguarda foi furiosamente perseguida como "sabotagem ideológica", tanto na URSS quanto na Alemanha fascista. Aliás as semelhanças entre a URSS stalinista e Alemanha fascista foram brilhantemente mostradas no filme documentário soviético Obiknoviénni Fachizm (parece-me que passou no Brasil como O Fascismo Ordinário), a que assisti mais de uma vez em Moscou e literalmentre sacudiu corações e mentes soviéticas na década de 60. Outro elemento em comum: a demago-

\footnotetext{
Cf. M. Kapústin, "Para uma Fenomenologia do Poder. Modelos Psicológicos de Autoritarismo: Ivã, o Terrível Stálin-Hitler", in Osmíslit kut Stálina (Entender o Culto Stálin), Moscou, Progress, |979, p. $372-40 \mid$
} 
gia social em sua forma mais evoluída caracterizou tanto o fascismo alemão quanto o stalinismo. Essa demagogia baseava-se em um amplo sistema de propaganda, que tinha a mentira como alimento principal. Não há como esquecer as palavras de Goebbels: uma mentira, mil vezes repetida, acaba se tornando verdade. Boris Schnaiderman cita as seguintes palavras do poeta Eduard Bagritzki: "Se o século exige do escritor 'mente', 'mente', se o século exige 'mata', 'mata!'. E o escritor cazaque Anuar Alimjanov arremata: "Nossa mentira foi duradoura, insistente, estatal...”. É evidente que as semelhanças não param por aí.

Graças à liberdade de expressão trazida pela glasnost, foi possível à imprensa publicar depoimentos pungentes sobre vítimas do terror stalinista, lançando luz sobre questões antes proibidas. Boris articula os fatos jornalísticos numa forma em que eles vão se disseminando ao longo do livro e combinando-se com documentos oriundos da literatura, das ciências e de outros campos do conhecimento e, à medida que avançamos na leitura do livro, vamos nos inteirando de fatos novos que só fazem aumentar as dimensões da tragédia que se abateu sobre toda uma sociedade, aniquilando pessoas fisicamente ou destruindo-as moralmente, instituindo um sistema de delação como norma de "bom comportamento" e criando nos indivíduos uma censura interna, além da terrível censura externa que tudo controlava. Assim, vemos um Tvardovski, poeta e intelectual muito estimado e considerado democrata, censurando Boris Pasternak, já depois de morto, pela publicação do romance Doutor Jivago no Ocidente, vemos Iúri Oliecha se autoavacalhando e reconhecendo uma "linha única" de comportamento do cidadão e do escritor como se essa "linha única" não fosse senão a expressão acabada do totalitarismo. A violência, institucionalizada como norma de conduta das autoridades no trato com os cidadãos, faz estes assumirem a culpa por atos que jamais haviam praticado. Assim, Meyerhold - o dramaturgo revolucionário que entendeu a revolução socialista como um ato de libertação das massas e das artes e, por isso, destruiu a distância entre público e palco - é preso, confessa-se espião a serviço da Inglaterra e do Japão e líder do "grupo anti-soviético da revista $L E F$ ", órgão de esquerda nas artes antes dirigido por Maiakóvski. A revista é porta-voz de uma facção da arte moderna, e seus integrantes, que apoiaram o poder soviético, recebem tratamento igual ao que a Alemanha hitlerista dispensaria à arte moderna. A prisão de Meyerhold é acompanhada de um ato de barbárie nazista com a invasão do seu apartamento e o assassinato de sua esposa Zinaída Reich, que ficou terrivelmente mutilada. Pouco depois o próprio Meyerhold seria fuzilado em 1940, já em plena guerra da URSS com a Alemanha. Assistimos, através da leitura, à destruição da velha guarda bolchevique, da qual o julgamento e posterior fuzilamento de Bukhárin, Rikov e outros revolucionários sinceros são apenas ilustrações sinistras do sistema que Boris chama de "máquina de triturar gente". Aliás, no Navajdiénie Yákovliev mostra, com dados, que eram freqüentes os fuzilamentos de membros do NKVD, isto é, os agentes da repressão de ontem acabavam sendo objeto da mesma máquina que antes haviam usado para destruir pessoas, numa confirmação macabra da instabilidade das pessoas numa sociedade totalitária, sugerida pela piada de abertura deste ensaio. E o mais trágico em tudo isso é que a maioria das pessoas considerava as vítimas do stalinismo como inimigos do povo, conforme o depoimento de M. A. Marov, juiz da Suprema Corte da URSS, ao jornal Izvéstia em 1987 e citado por Schnaiderman.

\section{MODELO MITOFOLCLÓRICO}

Aliás, esse rótulo de "inimigo do povo" decorre diretamente dos fundamentos do próprio sistema stalinista, que, necessitando de bodes-expiatórios para justificar o estado permanente de repressão que o caracterizou, foi buscar no folclore e nos mitos os modelos simbólicos capazes de entor- 
pecer as mentes e criar a maior empatia possível com o repressor e um clima de condenação popular antecipada da vítima. Ao esquema mitofolclórico o sistema stalinista tomou de empréstimo modelos como o "herói”, o "inimigo", ou "antagonista", o causador de danos transfigurado no "sabotador" ou no "espião", a “traição”, etc., em suma, uma série de elementos simbólicos que, evocados a torto e a direito, iriam provocar no psiquismo social a sensação de perigo ou desamparo que só seria aliviada com a inserção do arquétipo do grande chefe ou guia. Este é o depositário da plena sabedoria, é infalível, infinitamente bondoso e preocupado com o bem-estar e a segurança do povo, em quem está sempre pensando, segundo um poema popular. Ao inimigo aplica-se o estereótipo tradicional de inimigo do gênero humano, de monstro, de "inimigo do povo". A partir dessa imagemmodelo não há meio-termo: quem resvalar para a "esquerda" ou para a "direita" cairá naturalmente na categoria de "inimigo", e as regras do jogo, respaldadas por uma consciência social forjada na empatia do guia com os guiados, justificarão qualquer medida drástica aplicada aos "culpados", sobre quem, mais uma vez arquetipicamente, recairá a maldição de Can. "Justiçado" o pai, caberá ao filho carregar o estigma de "filho de inimigo do povo", tormento que lhe estará à espera onde quer que ele esteja ou pretenda ir. Foi essa a situação de milhares de soviéticos ao longo de decênios.

A tragédia foi o condimento mais comum no destino de muitos dos melhores escritores. Maiakóvski, Mikhail Bulgákov, Isaac Bábel, Olga Bergholtz, Marina Tzvietáieva, Óssip Mandelstam, apenas para ficar em alguns mais famosos, viram suas vidas transformadas em verdadeiro inferno. Em termos de inferno Bulgákov respondeu com o romance $O$ Mestre $e$ Margarida, onde aparecem parodiadas as figuras de Stálin, no diabo Voland, e a de Béria, no seu lugar-tenente Azazelo. Essa paródia de Bulgákov certamente não passou despercebida a Stálin. Uma das histórias mais terríveis foi certamente a do gran- de poeta Óssip Mandelstam, que Boris narra em detalhes sintéticos porém abrangentes. Foi Mandelstam quem disse que em país nenhum se dá tanta importância à poesia quanto na Rússia: aqui se fuzila um poeta por causa de um verso. E escreveu um poema sobre Stálin, do qual damos alguns dísticos:

“Sem sentir o país sob os pés vivemos nós A dez passos não se ouve a nossa voz,

Onde ela chega para meia conversinha Ali nos lembram o montanhês do Krêmlin.

Gordos como vermes são seus grossos

[dedos

E as palavras exatas qual do pud (2)

[os pesos

O bigode de barata em eterno rir

E os canos das botas sempre a luzir.

Ao seu redor, pescoços finos, os chefes

[canalhas

E ele brinca com os préstimos dessa

[gentalha.

Esse poema pôs Stálin furioso e desencadeou o processo que iria culminar na destruição total de Mandelstam. Como Boris mostra, o poeta resolveu escrever uma ode a Stálin e, como conta sua mulher Nadiéjda Mandelstam, ele passou a experimentar um verdadeiro martírio, porque, como era poeta de verdade, não conseguia violentar-se e descer ao estilo rasteiro dos poetas que decantavam a torto e a direito o "guia dos povos". Depois de esforços titânicos conseguiu escrever a tal ode, cujo conteúdo Boris expõe em palavras breves e se pergunta se isso seria uma tentativa de salvar-se ou uma identificação com o agressor. Uma coisa é certa: Stálin conseguira matar Mandelstam como poeta, matálo fisicamente já era questão secundária.

Curiosamente, esse vaivém de Mandelstam está rigorosamente enraizado na tradição da literatura russa. Púchkin, depois de escrever o célebre poema em que
2 Medida antiga igual a 16,3 quilos. 
conclama os dezembristas presos na Sibéria a acreditarem que a liberdade triunfará e eles terão seus nomes escritos nos escombros da autocracia, acaba escrevendo "Stansi" ("Estâncias"), uma ode a Nicolau I, o mesmo que executou e confinou os rebeldes, e nessa ode ele diz olhar para o futuro sem medo, na expectativa de glória e bondade. Dostoiévski esteve diante do pelotão de fuzilamento por atividades contra o governo, foi confinado na Sibéria e de lá voltou defendendo a monarquia. Tolstói ameaçou incendiar o mundo e acabou pregando a não-resistência ao mal. Maiakóvski foi o mais terrível crítico da burocracia nos anos 20, e acabou escrevendo, em 1925, o poema "Domói" ("Para Casa”), no qual pede que o Gosplan (órgão central encarregado do planejamento) transpire e lhe dê tarefas para o ano inteiro, isto é, planeje as suas atividades de poeta. Portanto, numa época em que ainda não havia o controle rigoroso das artes, pelo menos aquele que já encontramos nos anos 30, o poeta pede para ser controlado. Paradoxal não fosse trágico! Mas o mesmo Maiakóvski continuou fustigando a burocracia, que via como principal inimiga do socialismo, e acabou escrevendo $O$ Percevejo, produzindo uma visão pessimista da sociedade do futuro.

Ler Os Escombros e o Mito é um desafio que nos obriga o tempo todo a contextualizar os fatos na sofreguidão de apreendê-los, o que nos leva a constantes digressões pela história da Rússia e sua literatura. O método aparentemente simples com que mestre Boris concatena fatos e transita pelos mais diversos campos do conhecimento nos mostra uma erudição enciclopédica claramente voltada para um projeto grandioso de resgatar nomes e obras que foram silenciados nos esconderijos do spietzkhran, o famoso depósito especial que, quando aberto, revelou a existência de mais de 300 mil títulos de livros, mais de 560 mil títulos de revistas e pelo menos um milhão de jornais, em suma, descobriu-se ali uma espécie de sítio arqueológico da memória cultural soviética que o stalinismo havia condenado ao esquecimento. Como um arqueólogo que de repente se vê diante de uma descoberta inusitada, Boris mergulha nesse imenso acervo e vai estabelecendo pontes com obras publicadas dentro e fora da ex-URSS, sempre na tentativa de resgatar para o leitor o que a barbárie stalinista silenciou. Eaí nos deparamos com três momentos nessa trágica história cultural: o que foi publicado, mas sofreu mutilações, o que foi simplesmente proibido, e o que foi publicado fora da URSS. Em cada caso há um pouco de tragédia. Por falta de liberdade para publicar em casa suas próprias obras, muitos autores soviéticos constantemente as publicavam fora, correndo um duplo risco: risco de vida por ter sua obra publicada fora, e risco de deformação da própria obra em função de interesses escusos de editores oportunistas. Tanta coisa foi relegada ao ostracismo na URSS e publicada no Ocidente que o russo, para restaurar a ordem mais ou menos cronológica das suas publicações e reatar os fios da sua própria memória cultural, terá de desenvolver um trabalho conjunto com pesquisadores ocidentais, sem o que corre o risco de deixar que essa memória continue esfacelada. Porque o resgate do vivido na história e na ficção é o resgate da real experiência humana e, no caso dos russos, do próprio sentido da identidade da cultura nacional tão escamoteado por várias décadas de silêncio e falsificação dos fatos do cotidiano.

Os Escombros e o Mito é um livro de resgate, no qual o autor assume a posição de historiador e exegeta imparcial da cultura, capaz de ouvir todas as vozes abafadas ao longo de tantas décadas. Ao tratar a história cultural como um objeto polifônico, faz falarem as vozes que tiveram vez e as vozes que foram silenciadas e, assim, deixa que a História fale através das suas múltiplas facetas personificadas nas suas múltiplas vozes. Aí estão as vozes da prosa, da poesia, da crítica literária, da filosofia, do teatro, das artes plásticas, da música, do cinema, da fotografia, das mais diferentes tendências da literatura e das artes russas, em suma, os ecos daquele grande tempo que pareceram abafados ao longo de décadas mas de repente reapareceram como 
sombras redivivas a dizerem que a criação humana é imorredoura porque imortal é o homem na sua infinita inquietude. E isso graças à persistência de um homem que imprime à pesquisa aquela aristotélica paixão epistêmica sem a qual a própria existência humana perde o sentido.

Toda pesquisa, por mais ampla e abrangente que seja, deixa sempre algumas omissões. Coisa natural, porque nada é perfeito. No caso de Os Escombros e o Mito, que trata da cultura e do fim da União Soviética, senti falta de um ou outro nome, como Constantin Símonov, autor de $O s$ Vivos e os Mortos, uma espécie de ciclo romanesco que procura rever sem triunfalismo e com objetividade a história soviética a partir da experiência trágica da Segunda Guerra Mundial. Símonov foi um intelectual coerente, um homem que pensava com autonomia e, por sua importância, era tolerado pelas autoridades. Senti falta também de alguma referência a Iúri Bondariev, especificamente ao seu romance Tichiná (O Silêncio), uma das primeiras tentativas de ver criticamente a realidade soviética no início do período khruschoviano. Quando começou a perestroika-glasnost, Bondariev assumiu uma atitude radicalmente negativa em face das mudanças e acabou descambando para uma posição abertamente reacionária. Aliás foi idêntico o comportamento de Vassili Bielov e Valentin Raspútin, dois ótimos romancistas que não aceitaram as mudanças em curso e perderam o bonde da história. Há outras omissões que, evidentemente, não depõem contra um livro de alcance tão vasto que, em si, já é uma contribuição fundamental para se entender os descaminhos que redundaram no fim da primeira experiência socialista da história.

Os Escombros e o Mito é uma viagem pelo imenso território do sonho de milhões, uma viagem pelos espaços da façanha de tentar converter em realidade o milenar sonho humano de liberdade, igualdade e fraternidade, viagem dorida porque registra muito mais o desvirtuamento do sonho do que os seus acertos. Mas mostra também que se um povo é capaz de sair à rua para protestar contra a tentativa de fechamento de uma biblioteca, então nem tudo está perdido, e em meio aos escombros desse sonho ainda há algumas réstias alumiando sementes que um dia poderão medrar em jardim.

Boris Schnaiderman pertence àquele seleto grupo de pessoas sobre cuja mente o tempo parece não surtir efeito, pois sua escrita e sua capacidade de articular e associar fatos diversos e distantes continua com o mesmo vigor que encontramos no seu delicioso Guerra em Surdina. Ao fecharmos este Os Escombros e o Mito, já ficamos na expectativa do próximo livro.

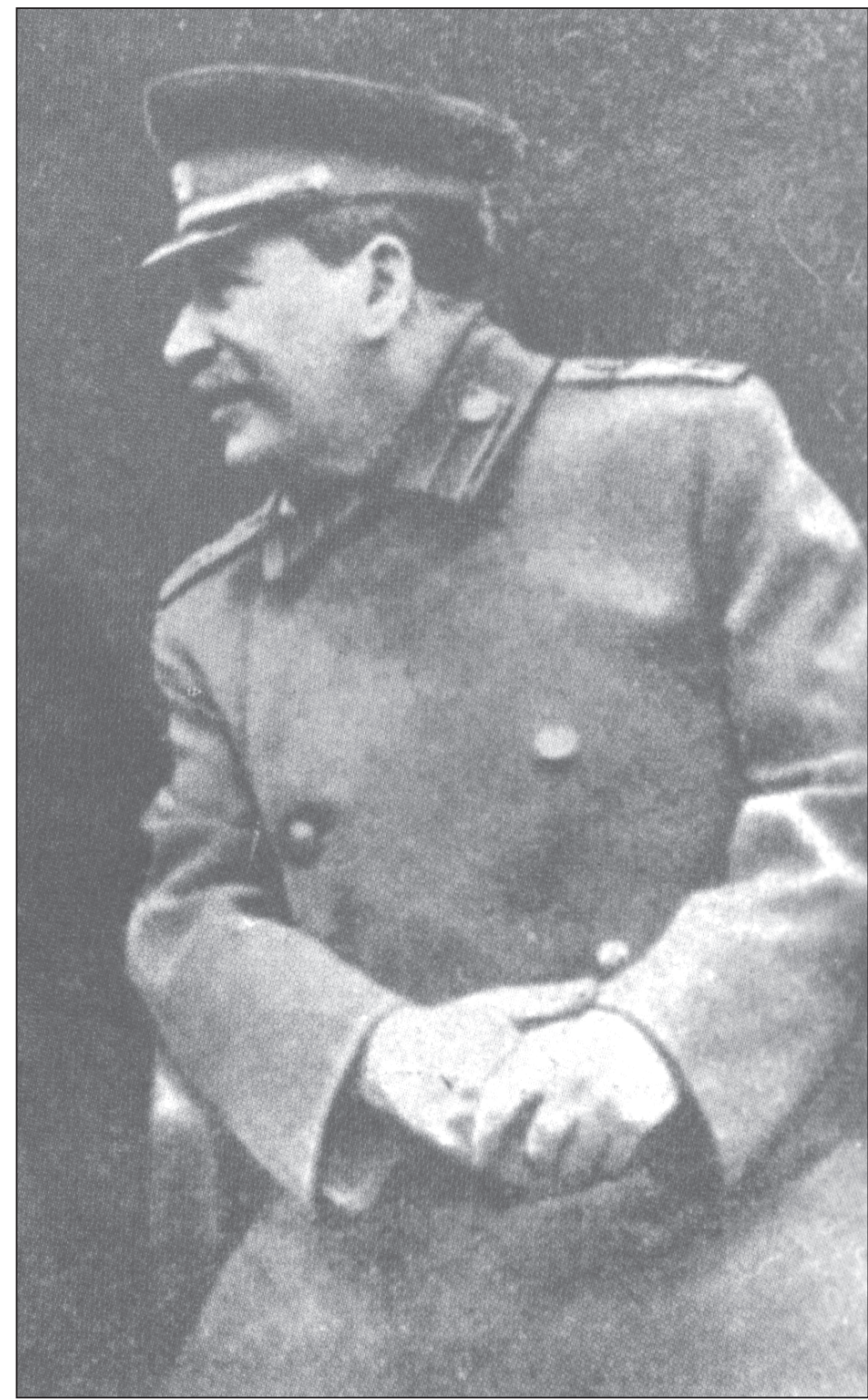

